\title{
Gaps in beliefs and practice in dyslipidaemia management in Japan, Germany, Colombia and the Philippines: insights from a web-based physician survey
}

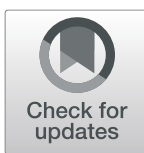

Philip J. Barter ${ }^{1}$, Shizuya Yamashita ${ }^{2}$, Ulrich Laufs ${ }^{3}$, Alvaro J. Ruiz ${ }^{4}$, Rody Sy ${ }^{5}$, Mark David G. Fang ${ }^{6}$, Emanuela Folco ${ }^{7}$, Peter Libby ${ }^{8}$, Yuji Matsuzawa ${ }^{9}$ and Raul D. Santos ${ }^{10,11^{*}}$ (iD

\begin{abstract}
Background: Implementing evidence-based management of dyslipidaemia is a challenge worldwide.

Objectives: To understand physician beliefs and behaviour and identify uncertainties in dyslipidaemia management across four world regions.

Methods: Web-based survey of 1758 physicians in Japan, Germany, Colombia and the Philippines who were selected randomly from existing databases. Key inclusion criteria were 1) for cardiologists and diabetes/ endocrinology specialists: $\geq 50$ dyslipidaemia patients examined in the last month; 2) for specialists in neurology/ neurosurgery/stroke medicine: $\geq 50$ dyslipidaemia patients and $\geq 20$ patients with a history of ischaemic stroke examined in the last month; and 3) for specialists in nephrology and general medicine: based at centres with $\geq 20$ beds and $\geq 50$ dyslipidaemia patients examined in the last month. The self-report survey covered dyslipidaemia management, target low-density lipoprotein cholesterol (LDL-C) levels in different patient groups, and statin safety. All physicians gave voluntary consent and all data were anonymised. Analysis was solely descriptive.
\end{abstract}

Results: The survey highlighted key areas of uncertainty in dyslipidaemia management in the four countries. These related to LDL-C targets in different patient groups, the safety of low LDL-C levels, the safety of statins, especially for effects on cognitive, renal and hepatic function and for haemorrhagic stroke risk, and lipid management strategies in patients with chronic kidney disease, including those with concomitant hypertriglyceridaemia.

Conclusions: This survey of physicians in Japan, Germany, Colombia and the Philippines has identified key gaps in knowledge about dyslipidaemia management. These relate to the safety of low LDL-C levels, the safety of statins, and lipid management of chronic kidney disease. The findings from this survey highlight the need for further education to improve the implementation of guideline recommendations for dyslipidaemia management.

Keywords: Low-density lipoprotein cholesterol, Atherosclerotic cardiovascular disease, Statins, Safety, Haemorrhagic stroke, Chronic kidney disease

\footnotetext{
* Correspondence: rauldsf@gmail.com

${ }^{10}$ Hospital Israelita Albert Einstein, São Paulo, Brazil

${ }^{11}$ Heart Institute -InCor, University of São Paulo Medical School Hospital, Av

Dr Enéas C. Aguiar 44, Sao Paulo, SP CEP-05403-900, Brazil

Full list of author information is available at the end of the article
}

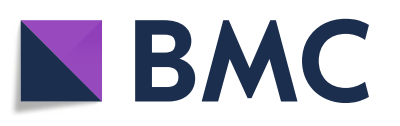

( ) The Author(s). 2020 Open Access This article is licensed under a Creative Commons Attribution 4.0 International License, which permits use, sharing, adaptation, distribution and reproduction in any medium or format, as long as you give appropriate credit to the original author(s) and the source, provide a link to the Creative Commons licence, and indicate if changes were made. The images or other third party material in this article are included in the article's Creative Commons licence, unless indicated otherwise in a credit line to the material. If material is not included in the article's Creative Commons licence and your intended use is not permitted by statutory regulation or exceeds the permitted use, you will need to obtain permission directly from the copyright holder. To view a copy of this licence, visit http://creativecommons.org/licenses/by/4.0/. The Creative Commons Public Domain Dedication waiver (http://creativecommons.org/publicdomain/zero/1.0/) applies to the data made available in this article, unless otherwise stated in a credit line to the data. 


\section{Introduction}

Extensive and robust evidence has established lowdensity lipoprotein cholesterol (LDL-C) as causal for atherosclerotic cardiovascular disease (ASCVD) [1]. Irrespective of therapeutic strategy, lowering LDL-C levels reduces the risk of ASCVD events, as demonstrated in major cardiovascular outcomes studies in very high-risk patients treated with a statin [2] or non-statin therapy (i.e. ezetimibe or proprotein convertase subtilisin/kexin type 9 [PCSK9] inhibitors) [3-5]. The safety of these LDL-lowering therapies has also been demonstrated [2-5]. Despite this overwhelming body of evidence, controversy persists regarding the role of LDL-C as a cause of ASCVD. Frequent, non-evidence-based assertions published in the media suggest that statins are unsafe and that lowering LDL-C to very low levels is dangerous [6]. There is also uncertainty regarding the veracity of adverse effects of statins, including statinassociated muscle symptoms [7, 8]. Similarly, safety concerns have been raised regarding novel therapies, including the PCSK9 inhibitors [9].

The World Heart Federation has developed a series of 'roadmaps' which aim to reduce cardiovascular disease in developing world regions. One of these roadmaps has focused on identifying barriers to effective cholesterol management gaps in knowledge and practice [10]. There is little information, however, regarding the beliefs and behaviour of physicians responsible for managing patients with dyslipidaemia in their routine practice. To address this issue, an online survey was conducted in Japan in 2017 by the Japan Atherosclerosis Society in collaboration with the International Atherosclerosis Society (IAS) to determine the attitudes and practice of physicians responsible for lipid management [11]. Subsequent to this, a second survey in Japan and surveys in Colombia, Germany and the Philippines were conducted by the IAS. These aimed to evaluate cultural differences among physicians in their beliefs and routine practice of managing dyslipidaemia.

\section{Methods}

This study was designed as a web-based survey, using an online questionnaire. The project was coordinated by the IAS. The IAS convened a committee, chaired by PB, RS, PL, SY, RDS, AR and UL, which was responsible for developing and implementing the survey in each country.

Physicians were selected randomly from existing databases in each country. In Japan, physician recruitment was conducted by CareNet, Inc., an online Japaneselanguage medical information service for physicians. All prospective participants were registered members of CareNet, Inc., and received an email introducing the study and inviting them to participate. In Germany, physicians were selected from a market research panel of approximately 17,000 doctors. In Colombia, a local healthcare fieldwork partner recruited physicians via email and telephone. Finally, in the Philippines, physicians were recruited from a database created from an online 'e-survey' of internists, cardiologists and vascular specialists attending annual clinical conventions, or by questionnaires distributed at a workshop for cardiologists, and a local chapter convention for internists. In all countries, physicians who met the following criteria were accepted for inclusion in the survey: (i) expertise in cardiology, diabetes or endocrinology and treating $\geq 50$ patients with dyslipidaemia in the previous month; (ii) expertise in neurology, neurosurgery or stroke medicine and treating $\geq 50$ patients with dyslipidaemia and $\geq 20$ patients with a history of ischaemic stroke in the previous month; and (iii) expertise in nephrology and general internists based at hospitals with $\geq 20$ beds and treating $\geq 50$ patients with dyslipidaemia in the previous month. All physicians gave voluntary consent before participation.

The study used a self-report web-based survey, which required 15-30 min for completion (Table 1). Briefly, the survey comprised 23 multiple choice questions that aimed to investigate beliefs and behaviour in the management of dyslipidaemia. These included questions relating to the role of LDL-C in ASCVD, target LDL-C levels in different patient groups, safety issues relating to low LDL-C levels and statin use, awareness and management of familial hypercholesterolaemia (FH), and current practice for the management of hypertriglyceridaemia in patients with chronic kidney disease (CKD). Data were anonymised and analysed descriptively by the authors. Categorical data were described as absolute numbers and percentages. No formal statistical analyses comparing different countries or different medical specialties were performed.

\section{Results}

A total of 1758 physicians, 508 in Japan, 500 in Germany, 345 in Colombia, and 405 in the Philippines, took part in the survey. Across all four countries, most respondents were either general physicians (33\%) or cardiologists (22\%) (Table 2). Results are summarised below for findings that show either agreement or uncertainty between countries.

\section{Agreement between countries}

There was universal agreement in all four countries (9599\% of respondents) that an elevated LDL-C level is an important cause of coronary disease and ischaemic stroke. Recent efforts aimed at educating clinicians about $\mathrm{FH}$ have improved awareness, as $>95 \%$ of respondents in all four countries were aware about $\mathrm{FH}$, and between 
Table 1 Web-based survey used to investigate beliefs and behaviour in dyslipidaemia management in the four countries*

Question $^{\text {a }}$
2. Do you believe that elevated LDL cholesterol is an important cause of
coronary disease and ischaemic stroke?
3. Concerning use of statin, do you have concerns related to any of the
following. (More than one item can be selected)?

4. Do you have concerns about lowering LDL cholesterol levels in patients with

5. Do you think statins have any effect on cognitive function?

6. Please indicate the percentage of patients who cannot use statins continuously due to adverse effects (such as muscle symptoms, etc.).

7. Please indicate your target level of $L D L$ cholesterol after initiation of drug therapy in the following patient groups

8. Do you have concerns about safety if the LDL cholesterol is below the following levels?

9. Do you think markedly low LDL cholesterol levels affect the incidence of haemorrhagic stroke?

10. How much does the LDL cholesterol level affect the risk of inducing atherosclerotic cardiovascular diseases?

11 Do you sometimes use "non-HDL cholesterol level" as a risk index of atherosclerotic cardiovascular diseases (ASCVD, coronary artery diseases, non-cardiogenic cerebral infarction) or a therapeutic efficacy index during your medical practice?

12. For Japan: Concerning "Comprehensive risk management chart for the prevention of cerebro- and cardiovascular diseases" developed in 2015 mainly by The Japanese Society of Internal Medicine, please inform us about the status of your recognition/use of the chart.

For Germany: Concerning the European Guidelines (ESC/EAS) for lipid management.

For Colombia: Concerning the AHA/ACC Guidelines for lipid management

13. Concerning Familial Hypercholesterolaemia (FH, one type of primary hyperlipidaemia), which best reflects your practice?

\section{Responses}

Yes/No/Uncertain

Increase of the risk of haemorrhagic stroke - Increase of the risk of cognitive impairment

Increase of the risk of new onset diabetes

- Development of muscle disorder

Increased risk of hepatic disease

- Others (Please specify)

Do not have any concern

- Haemorrhagic stroke: Yes/No/Uncertain

- Ischaemic stroke: Yes/No/Uncertain

- Transient ischaemic attack (TIA): Yes/No/Uncertain

- Subarachnoid haemorrhage: Yes/No/Uncertain

Yes/No/Uncertain

$0 \%$ (I have no statin-intolerant patients)

$\geq 0.1$ to $<5 \%$

$\geq 5$ to $<10 \%$

$\geq 10$ to $<15 \%$

$\geq 15$ to $<20 \%$

$\geq 20 \%$

- A history of any coronary artery disease: The target level of LDL cholesterol should be $<\mathrm{mg} / \mathrm{dl}$ (please specify)

- Without a history of coronary artery disease but with a history of diabetes mellitus/chronic kidney disease/ischaemic stroke/peripheral artery disease: The target level of $L D L$ cholesterol should be $<\mathrm{mg} / \mathrm{dl}$ (please specify)

- Without a history of the conditions listed above: The target level of LDL cholesterol should be $<\mathrm{mg} / \mathrm{dl}$ (please specify)

$20 \mathrm{mg} / \mathrm{dL}(0.52 \mathrm{mmol} / \mathrm{L})$

$.30 \mathrm{mg} / \mathrm{dL}(0.78 \mathrm{mmol} / \mathrm{L})$

$40 \mathrm{mg} / \mathrm{dL}(1.03 \mathrm{mmol} / \mathrm{L})$

$50 \mathrm{mg} / \mathrm{dL}(1.29 \mathrm{mmol} / \mathrm{L})$

$60 \mathrm{mg} / \mathrm{dL}(1.55 \mathrm{mmol} / \mathrm{L})$

$.70 \mathrm{mg} / \mathrm{dL}(1.80 \mathrm{mmol} / \mathrm{L})$

Other value $[\mathrm{mg} / \mathrm{dL}$ or $\mathrm{mmol} / \mathrm{L}]$

Does not have any opinion

\section{Yes/No/Uncertain}

Affects the risk significantly

Affects the risk moderately

Uncertain

Affects the risk to a small extent

Does not affect the risk

- non-HDL cholesterol level is not used

non-HDL cholesterol level is sometimes used as "a risk index of ASCVD"

- non-HDL cholesterol level is sometimes used as "a therapeutic efficacy index."

- non-HDL cholesterol level is sometimes used as both "a risk index of ASCVD" and "a therapeutic efficacy index."

- I know about this chart and am actually using it

- I know about this chart, but have never used it

I do not know about this chart.

I know about the guidelines and I am actually using them

- I know about the guidelines, but I have never used them.

- I do not know about the guidelines

I know about the guidelines and I am actually using them

- I know about the guidelines, but I have never used them.

- I do not know about the guidelines

. I know about FH and have patients with FH (which was found by my diagnosis) and am engaged in their treatment. 
Table 1 Web-based survey used to investigate beliefs and behaviour in dyslipidaemia management in the four countries* (Continued)

\begin{tabular}{|c|c|}
\hline Question $^{a}$ & Responses \\
\hline & $\begin{array}{l}\text { I know about FH and have referred patients with suspected FH to some } \\
\text { other medical institution/physician. } \\
\text { I know about } \mathrm{FH} \text { but have never seen a patient with suspected FH. } \\
\text { I do not know about FH. }\end{array}$ \\
\hline $\begin{array}{l}\text { 14. When you make a diagnosis of FH in an adult patient (15-year-old or } \\
\text { older), do you perform the followings? (More than one item can be } \\
\text { selected) }\end{array}$ & $\begin{array}{l}\text { Palpation of Achilles tendon } \\
\text { X-ray photography of Achilles tendon } \\
\text { - Take a family history of hyper-LDL-cholesterolaemia } \\
\text { - Take a family history of FH } \\
\text { - Take a family history of premature coronary artery diseases } \\
\text { - None of the above }\end{array}$ \\
\hline $\begin{array}{l}\text { 15. Do you think patients with FH have an increased incidence of } \\
\text { ischaemic stroke? }\end{array}$ & Yes/No/Uncertain \\
\hline 16. Do you think statins have any adverse effects on renal function? & Yes/No/Uncertain \\
\hline $\begin{array}{l}\text { 17. Do you think the lowering of LDL cholesterol reduces ASCVD events } \\
\text { in patients with CKD? }\end{array}$ & Yes/No/Uncertain \\
\hline $\begin{array}{l}\text { 18. If yes, is LDL cholesterol lowering therapy effective for patients with } \\
\text { any stage of CKD? }\end{array}$ & Yes/No/Uncertain \\
\hline $\begin{array}{l}\text { 19. What do you think is the target LDL cholesterol level for primary } \\
\text { prevention of the patients with CKD? }\end{array}$ & $\begin{array}{l}<140 \mathrm{mg} / \mathrm{dL}(<3.62 \mathrm{mmol} / \mathrm{L}) \\
<120 \mathrm{mg} / \mathrm{dL}(<3.10 \mathrm{mmol} / \mathrm{L}) \\
<100 \mathrm{mg} / \mathrm{dL}(<2.6 \mathrm{mmol} / \mathrm{L}) \\
<70 \mathrm{mg} / \mathrm{dL}(<1.8 \mathrm{mmol} / \mathrm{L}) \\
\text { Medicate without setting the target LDL cholesterol level }\end{array}$ \\
\hline $\begin{array}{l}\text { 20. Do you think the target } L D L \text { cholesterol level is different between } \\
\text { patients with different CKD stage? }\end{array}$ & Yes/No/Uncertain \\
\hline $\begin{array}{l}\text { 21. Do you think there is a clinical benefit to treat CKD patients with } \\
\text { hypertriglyceridaemia? }\end{array}$ & Yes/No/Uncertain \\
\hline 22. How do you treat CKD patients with hypertriglyceridaemia? & $\begin{array}{l}\text { Use statins } \\
\text { Use fibrates } \\
\text { - Use nicotinic acid derivatives } \\
\text { - Use n-3 polyunsaturated fatty acid } \\
\text { - Manage through lifestyle modification without medications }\end{array}$ \\
\hline 23. Do you reduce the dose of statins in patients with CKD? & Yes/No/Uncertain \\
\hline
\end{tabular}

${ }^{a}$ Question 1 confirmed eligibility to participate in the survey: i.e. Concerning the patients you examined for the latest one month, please inform us the numbers of the followings

Number of patients with dyslipidaemia

Number of patients with a history of ischaemic stroke

Number of patients with (or with a history of) coronary heart disease

The number of patients you examined

The number of patients receiving drug treatment for dyslipidaemia

56\% (in the Philippines) and 85\% (in Germany) of physicians either treated $\mathrm{FH}$ patients or referred them to a specialist centre. Most physicians (81-92\%) believed that $\mathrm{FH}$ patients were also at increased risk of ischaemic stroke (Fig. 1).
There was also agreement between all four countries that lowering LDL-C reduces the risk of ASCVD events in CKD patients (ranging from $70 \%$ of respondents in Germany to $94 \%$ in the Philippines) (Fig. 1). Most respondents believed that there was a benefit from using

Table 2 Number of eligible physicians participating in the survey, summarised by country and specialty

\begin{tabular}{|c|c|c|c|c|c|}
\hline & Japan & Germany & Colombia & Philippines & Total (\%) \\
\hline \multicolumn{6}{|l|}{ Specialty } \\
\hline Cardiologists & 103 & 100 & 55 & 122 & $380(22 \%)$ \\
\hline Endocrinologists & 103 & 100 & 40 & 42 & $285(16 \%)$ \\
\hline Neurologists & 102 & 100 & 70 & 7 & $279(16 \%)$ \\
\hline Nephrologists & 100 & 100 & 20 & 12 & $232(13 \%)$ \\
\hline General physicians & 100 & 100 & 160 & 222 & $582(33 \%)$ \\
\hline Total & 508 & 500 & 345 & 405 & 1758 \\
\hline
\end{tabular}




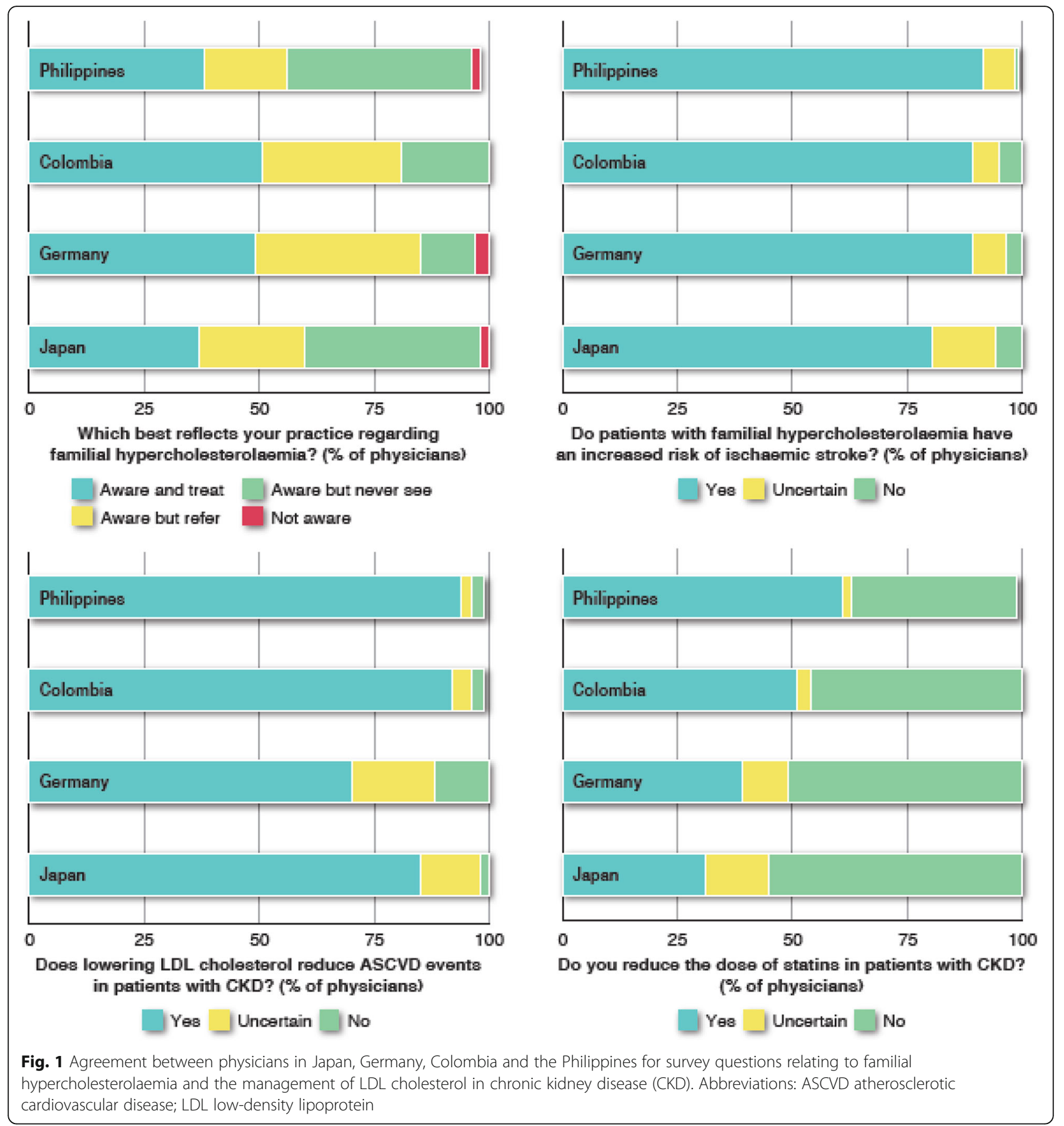

statins at any stage of CKD. Across the countries, between $31 \%$ (in Japan) and $61 \%$ (in the Philippines) of respondents believed that the statin dose should be reduced in patients with CKD (Fig. 1).

\section{Uncertainty between countries}

The survey identified several areas of uncertainty in dyslipidaemia management, both within and across the four countries.

\section{Target LDL-C levels}

In people with established coronary heart disease, the target LDL-C level proposed by physicians varied, from $2.48 \mathrm{mmol} / \mathrm{L}(96 \mathrm{mg} / \mathrm{dL})$ in Japan, $2.22 \mathrm{mmol} / \mathrm{L}(86 \mathrm{mg} /$ $\mathrm{dL})$ in Germany, $2.10 \mathrm{mmol} / \mathrm{L}(85 \mathrm{mg} / \mathrm{dL})$ in the Philippines, to $2.07 \mathrm{mmol} / \mathrm{L}(80 \mathrm{mg} / \mathrm{dL}$ ) in Colombia. Respondents in three countries believed that the target LDL-C level should be higher in people with diabetes, CKD or peripheral artery disease but without coronary heart disease $(2.84 \mathrm{mmol} / \mathrm{L}[110 \mathrm{mg} / \mathrm{dL}]$ in Japan, 2.43 
$\mathrm{mmol} / \mathrm{L}[94 \mathrm{mg} / \mathrm{dL}$ ] in Germany, and $2.25 \mathrm{mmol} / \mathrm{L}$ [87 $\mathrm{mg} / \mathrm{dL}$ ] in Colombia). In primary prevention patients without these conditions, the proposed target LDL-C levels were higher, ranging from $3.39 \mathrm{mmol} / \mathrm{L}(131 \mathrm{mg} / \mathrm{dL})$ in Japan, $3.34 \mathrm{mmol} / \mathrm{L}(129 \mathrm{mg} / \mathrm{dL})$ in Germany, 2.97 $\mathrm{mmol} / \mathrm{L}(115 \mathrm{mg} / \mathrm{dL})$ in Colombia and $2.72 \mathrm{mmol} / \mathrm{L}$ (105 $\mathrm{mg} / \mathrm{dL}$ ) in the Philippines. In Japan, Germany and the Philippines less than half of the respondents, versus $75 \%$ in Colombia, used non-high-density lipoprotein cholesterol either to determine global risk or as a therapeutic target.

\section{Management of CKD}

Beliefs regarding the target LDL-C level in CKD patients varied between the four countries. In Japan, $67 \%$ of respondents believed that the target LDL-C should be $<3.1 \mathrm{mmol} / \mathrm{L}(120 \mathrm{mg} / \mathrm{dL})$. In the other three countries, between 40\% (in the Philippines) and 57\% (in Colombia) believed that the target LDL-C should be $<2.6 \mathrm{mmol} / \mathrm{L}$ (100 $\mathrm{mg} / \mathrm{dL}$ ), and between 21\% (in Germany) and 27\% (in Colombia and the Philippines) believed that the target LDL-C should be $<1.8 \mathrm{mmol} / \mathrm{L}$ ( $70 \mathrm{mg} / \mathrm{dL}$ ). The perceived clinical benefit of treating CKD patients with hypertriglyceridaemia also varied between countries, from $91 \%$ in Colombia to $42 \%$ in Germany. While the pharmacotherapeutic options for hypertriglyceridaemia in CKD were similar in the four countries (statins, fibrates and omega-3 fatty acids), $30 \%$ of physicians in Germany believed that lifestyle modification alone was the most appropriate treatment for CKD.

\section{Safety of low LDL-C levels}

About half of the respondents in the four countries had concerns about the safety of low LDL-C levels $(\leq 1.29$ $\mathrm{mmol} / \mathrm{L}$ or $\leq 50 \mathrm{mg} / \mathrm{dL}$ ) (Table 3 ). The risk for haemorrhagic stroke with low LDL-C levels was a key concern, although there was also uncertainty (40\% of clinicians in Japan and Germany, 38\% in Colombia and $44 \%$ in the Philippines were uncertain about this issue).

Table 3 Percentage of physicians with concerns about safety below the following LDL-C levels, summarised by country

\begin{tabular}{lllll}
\hline & Japan & Germany & Colombia & Philippines \\
\hline $\begin{array}{l}\text { LDL-C level mmol/L } \\
(\mathrm{mg} / \mathrm{dL})\end{array}$ & \multicolumn{3}{l}{ (\% of physicians) } \\
$<0.52(20)$ & 2 & 13 & 10 & 13 \\
$<0.78(30)$ & 8 & 10 & 8 & 10 \\
$<1.03(40)$ & 16 & 11 & 14 & 8 \\
$<1.29(50)$ & 23 & 14 & 14 & 13 \\
$<1.55(60)$ & 17 & 5 & 22 & 7 \\
$<1.80(70)$ & 7 & 7 & 12 & 9 \\
Other & 1 & 3 & 2 & 0 \\
No opinion & 26 & 38 & 26 & 34 \\
\hline
\end{tabular}

\section{Statin safety}

Physicians in all four countries recognised that a small proportion of patients are unable to use statins continuously due to adverse effects. Estimates of the percentage of affected patients varied from $<5 \%$ reported by most respondents in Japan, Colombia and the Philippines, to $5-15 \%$ reported by half of respondents in Germany. The survey highlighted uncertainty in all four countries regarding the effects of statins on cognitive, renal, and hepatic function (Fig. 2). A substantial proportion of respondents in each of the four countries was uncertain whether statins adversely affect cognitive function $(24 \%$ in Germany, 26\% in Colombia, 36\% in the Philippines and $42 \%$ in Japan), or renal function (16\% in Germany, $8 \%$ in Colombia, $13 \%$ in the Philippines and $36 \%$ in Japan).

\section{Discussion}

This survey has identified gaps in knowledge and behaviour amongst physicians managing dyslipidaemia in Japan, Germany, Colombia and the Philippines (Summary figure (Fig. 3)).

It is reassuring that there is almost universal agreement across all four countries regarding the causality of LDL-C in ASCVD. In addition, there is evidence of improvement in $\mathrm{FH}$ awareness and care, possibly reflecting a renewed focus from expert consensus groups [12, 13]. This builds on findings from the initial physician survey in Japan, which highlighted underdiagnosis of $\mathrm{FH}$, especially among general practitioners, as an issue [11]. Despite the availability of well-developed evidence-based guidelines for dyslipidaemia management in each country or respective world region, areas of disagreement/uncertainty were identified [14-17]. These related to the safety of statin therapy, the safety of very low LDL-C levels, and dyslipidaemia management in CKD.

Consistent with the initial survey of physician attitudes in dyslipidaemia management in Japan [11], there were concerns regarding the safety of very low LDL-C levels attained on a statin (with or without other lipid modifying therapy). In the current report, these primarily focus on cognitive and renal function, as well as the risk of haemorrhagic stroke. While there is compelling evidence that a very low level of LDL-C may increase the risk of haemorrhagic stroke [18], especially in Asians [19], it is pertinent that there was no increase in risk at very low LDL-C levels attained by adding ezetimibe [3] or a PCSK9 inhibitor $[4,5]$ to background statin therapy in major clinical trials. Moreover, the well-documented reduction in the risk of ischaemic stroke in individuals who attain very low LDL-C levels outweighs any possible increase in the risk of a haemorrhagic stroke $[2-4,20]$. With respect to cognitive adverse effects, the EBBINGHAUS study specifically investigated the 


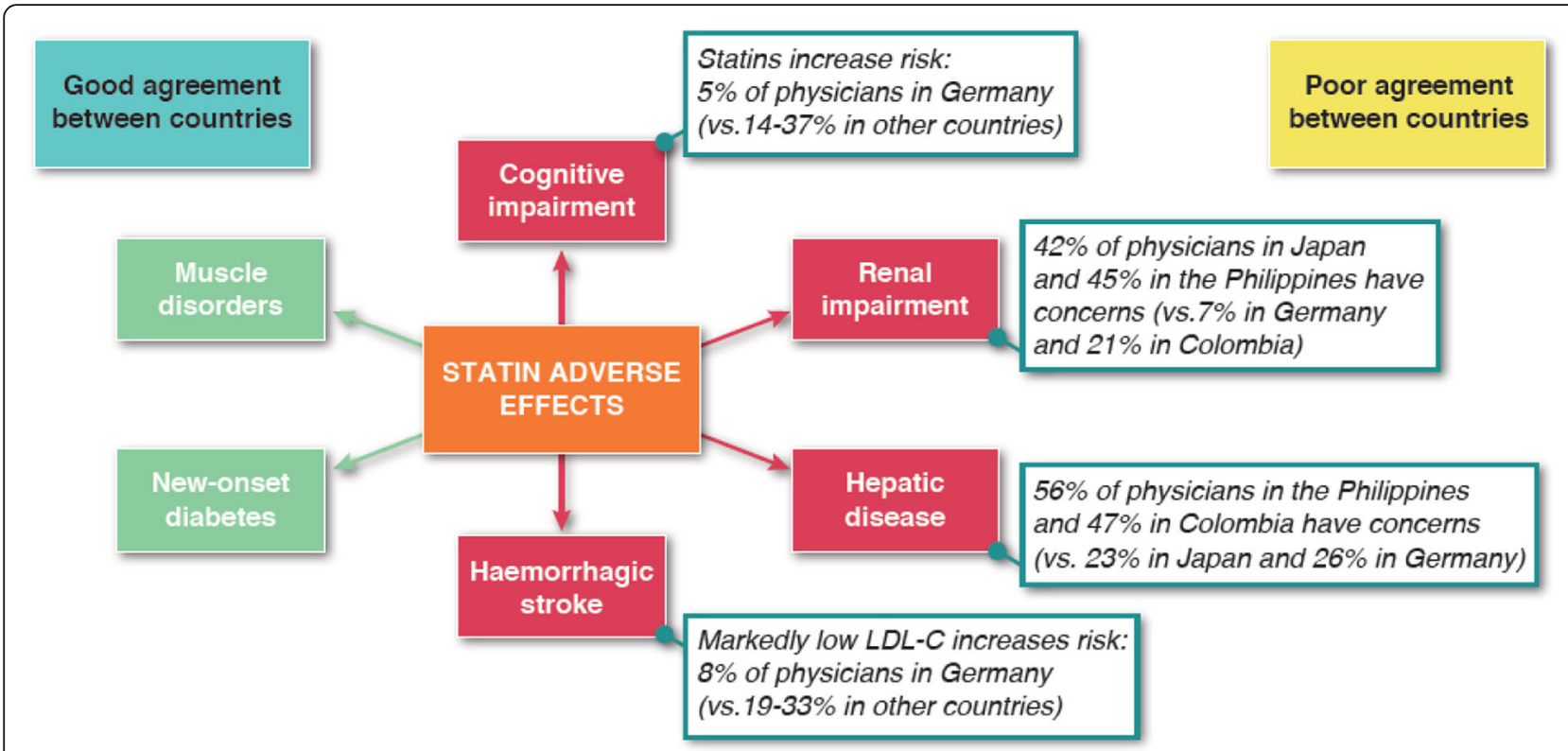

Fig. 2 Agreement and disagreement between physicians in Japan, Germany, Colombia and the Philippines relating to the adverse effects of statin therapy. Abbreviations: LDL-C low-density lipoprotein cholesterol

effect of very low LDL-C levels using a computerised battery of tests for a range of cognitive domains including episodic and working memory, executive function, psychomotor speed and attention. This study showed no change in cognitive function even at very low LDL-C

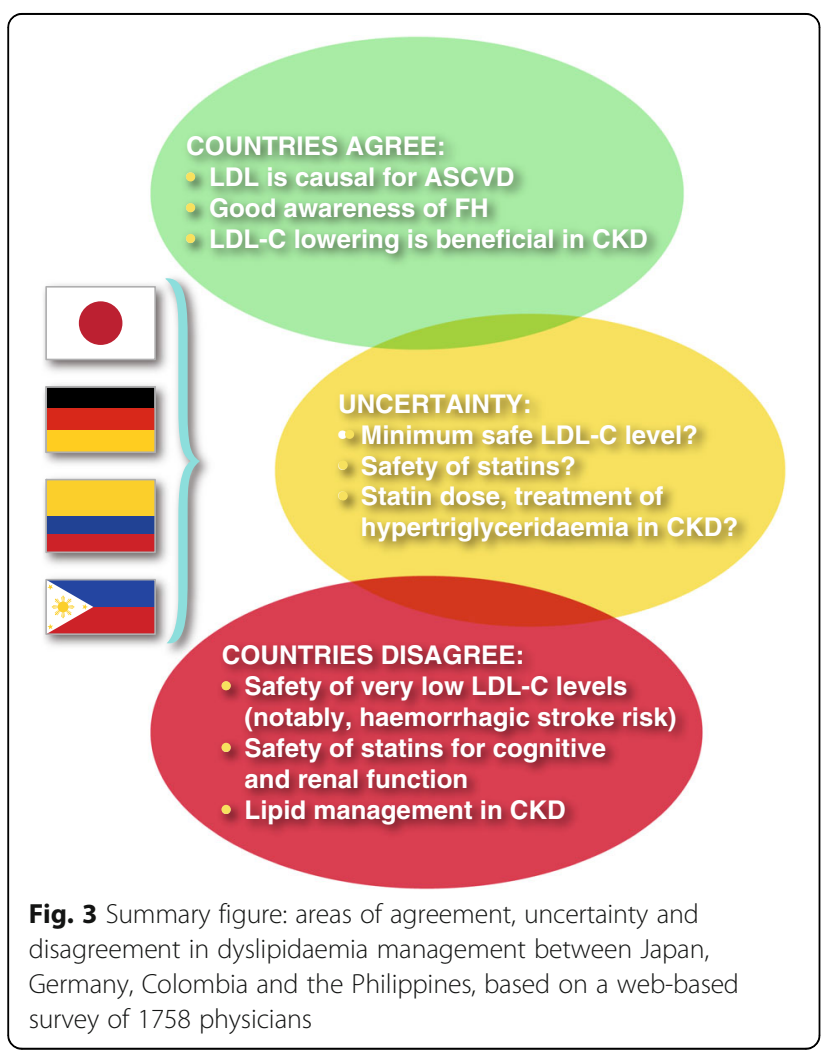

levels $(0.28-0.44 \mathrm{mmol} / \mathrm{L}$ or $11-17 \mathrm{mg} / \mathrm{dL})$ attained with the addition of a PCKS9 inhibitor [21]. It should be noted, however, that the duration of treatment with a PCSK9 inhibitor in this trial was relatively short and that longerterm data are still needed. There is no convincing evidence that the use of statins or attainment of a low LDL-C level causes renal dysfunction [2, 8]. Indeed, subgroup analyses from several major studies suggest that statins may have a renoprotective effect which merits further study [22].

Management of dyslipidaemia in CKD patients was another area of uncertainty in all four countries. There was a lack of consensus regarding the perceived need to reduce the statin dose in patients with CKD, the need for different LDL-C target levels depending on the stage of the CKD, as well as the clinical benefit of treating hypertriglyceridaemia in CKD patients.

The authors recognise several limitations relating to the methodology of this survey. First, physicians were recruited to the survey using a variety of approaches, including random selection from existing databases, contact via email and/or telephone, and recruitment from expert-led workshops. Second, the survey was selfreport. Another potential source of relates to the distribution of specialties in the countries. Whereas in Japan and Germany there was an equal distribution across all specialties, in both Colombia and the Philippines, about half of all physicians were general physicians (46 and $55 \%$, respectively). Thus, the study findings may have been influenced by differences in the knowledge base between different specialties. Indeed, this was evident in 
the initial survey conducted in Japan, in which cardiologists were shown to treat LDL-C more aggressively than those in other specialties or in general practice. Results from the PERCRO-DOC survey of more than 1300 randomly selected physicians in Croatia also indicated differences in the approach to cardiovascular prevention between general practitioners and hospital specialists. General practitioners were less likely to refer to guidelines compared with cardiologists and internists [23].

The extent to which the findings from this survey can be extrapolated to other countries is uncertain. Despite this, the results provide several important 'take-home' messages for physicians. In all four countries, there are key gaps in beliefs and practice that contribute to a roadblock for treatment of dyslipidaemia in people at high risk of ASCVD [10]. This was also evident in the initial physician survey; while most physicians $(\sim 80 \%)$ believed they treated dyslipidaemia appropriately, only about half (53.3\%) knew the LDL-C target for high-risk patients. Moreover, only about half recognised the level at which high-density lipoprotein cholesterol was a marker of increased risk [11]. Similar findings were reported in the PERCRO-DOC survey [23]. Importantly, retrospective analysis of LDL-C goal attainment in more than 4000 outpatients in Italy in a real-world setting showed that less than $10 \%$ of patients considered at high or very high risk attained guideline-recommended LDL-C goals [24]. Real-world data derived from the Cegedim Longitudinal Practice Database in Germany, as well as observational findings from 18 countries outside Western Europe, also indicated inadequate use of lipid lowering therapy in high and very highrisk patients $[25,26]$.

Taken together, these findings highlight the need for educational programmes to increase awareness of the current evidence base supporting dyslipidaemia management. Where evidence is lacking, research is needed to address uncertainties, as well as education to put unresolved issues in perspective. Comparable surveys are also needed in North America, Eastern Europe and the Middle East to extend knowledge and improve dyslipidaemia management across all world regions.

\section{Conclusions}

In conclusion, this survey provides a 'snapshot' of the beliefs and behaviour of physicians in Japan, Germany, Colombia and the Philippines who are involved in managing patients with dyslipidaemia in their routine practice. The findings highlight key areas of need for further education and research. The results provide a rationale for similar surveys in other countries, as well as followup surveys to assess the impact of any educational programmes and activities on these gaps in belief and practice in dyslipidaemia management.

\section{Abbreviations}

ASCVD: Atherosclerotic cardiovascular disease; CKD: Chronic kidney disease; FH: Familial hypercholesterolaemia; LDL-C: Low-density lipoprotein cholesterol; PCSK9: Proprotein convertase subtilisin/kexin type 9

\section{Acknowledgements}

Not applicable.

\section{Authors' contributions}

PJB, RDS and PL conceived the study and analysed the data. All authors were involved in drafting and review of the manuscript. The authors read and approved the final manuscript.

\section{Funding}

This study was supported by an unrestricted grant from Amgen to the International Atherosclerosis Society. In the Philippines, Merck Sharpe \& Dome (Philippines) helped in setting up the platform for the questionnaires and the Philippine Lipid and Atherosclerosis Society provided financial support for the survey.

RDS is a recipient of a scholarship from the Conselho Nacional de Pesquisa e Desenvolvimento Tecnologico (CNPq), Brazil, process \# 303734/2018-3.

\section{Availability of data and materials}

The datasets used and/or analysed during the current study are available from the corresponding author on reasonable request.

\section{Ethics approval and consent to participate}

Ethics approval was not applicable. All physicians participating in the survey gave voluntary consent and data were fully anonymised.

\section{Consent for publication}

Not applicable.

\section{Competing interests}

PJB has received honoraria for lectures given for Amgen, Pfizer and Sanofi Regeneron and has been a member of Scientific Advisory Boards for Amgen, Merck, Pfizer and Sanofi Regeneron. SY has received grants or honoraria for lectures from Kowa, Otsuka Pharmaceutical, Shionogi \& Co, Bayer Yakuhin, MSD K. K, Takeda, Sanwa Kagaku Kenkyusho Co, Ono Pharmaceutical Company, Astellas Pharma, Daiichi-Sankyo, Mochida, Kaken, Astra Zeneca, Skylight Biotech, Astellas Amgen, Sanofi, Aegerion, and Kyowa Medex. UL has received honoraria for consulting or lectures from Amgen, Bayer, Boehringer, Sanofi/Regeneron. AJR has received honoraria for lectures from Sanofi, Pfizer, AstraZeneca and Valentech and payment for participation in advisory boards from Sanofi and Amgen. RS has received research grant and lecture honorarium from Sanofi, MSD and Pfizer. PL is an unpaid consultant to, or involved in clinical trials for Amgen, AstraZeneca, Esperion Therapeutics, Ionis Pharmaceuticals, Kowa Pharmaceuticals, Novartis, Pfizer, Sanofi-Regeneron XBiotech, Inc. PL is a member of scientific advisory boards for Amgen, Athera biotechnologies, Corvidia Therapeutics, DalCor Pharmaceuticals, IFM Therapeutics, Kowa Pharmaceuticals, Olatec Therapeutics, Medimmune, Novartis and his laboratory has received research funding in the last 2 years from Novartis. YM has received honoraria for consulting or lectures from Teijin Pharma and Kowa. RDS has received honoraria for consulting, speaker activities and or research from Ache, Amgen, Astra Zeneca, Esperion, Kowa, Novo-Nordisk, Merck, MSD, Pfizer, PTC and Sanofi/Regeneron. MDGF and EF have no conflicts to declare.

\section{Author details}

${ }^{1}$ School of Medical Sciences, University of New South Wales, Sydney, Australia. ${ }^{2}$ Rinku General Medical Center and Osaka University Graduate School of Medicine, Osaka, Japan. ${ }^{3}$ Universitatsklinikum Leipzig, Leipzig, Germany. ${ }^{4}$ Pontificia Universidad Javeriana, Bogota, Colombia. ${ }^{5}$ College of Medicine, University of the Philippines-Manila, Manila, the Philippines. ${ }^{6}$ Cardinal Santos Medical Center, San Juan City, MetroManila, the Philippines. ${ }^{7}$ International Atherosclerosis Society, Viale Piave 35, Milan, Italy. ${ }^{8}$ Brigham and Women's Hospital, Harvard Medical School, Boston, USA. ${ }^{9}$ Sumitomo Hospital, Osaka, Japan. ${ }^{10}$ Hospital Israelita Albert Einstein, São Paulo, Brazil.

${ }^{11}$ Heart Institute -InCor, University of São Paulo Medical School Hospital, Av Dr Enéas C. Aguiar 44, Sao Paulo, SP CEP-05403-900, Brazil. 
Received: 3 January 2020 Accepted: 22 April 2020

Published online: 10 June 2020

\section{References}

1. Ference BA, Ginsberg HN, Graham I, Ray KK, Packard CJ, Bruckert E, et al. Low-density lipoproteins cause atherosclerotic cardiovascular disease. 1. Evidence from genetic, epidemiologic, and clinical studies. A consensus statement from the European atherosclerosis society consensus panel. Eur Heart J. 2017:38:2459-72

2. Collins R, Reith C, Emberson J, Armitage J, Baigent C, Blackwell L, et al. Interpretation of the evidence for the efficacy and safety of statin therapy. Lancet. 2016:388:2532-61.

3. Cannon CP, Blazing MA, Giugliano RP, McCagg A, White JA, Theroux P, et al. Ezetimibe added to statin therapy after acute coronary syndromes. N Engl J Med. 2015;372:2387-97.

4. Sabatine MS, Giugliano RP, Keech AC, Honarpour N, Wiviott SD, Murphy SA, et al. Evolocumab and clinical outcomes in patients with cardiovascular disease. N Engl J Med. 2017;376:1713-22.

5. Schwartz GG, Steg PG, Szarek M, Bhatt DL, Bittner VA, Diaz R, et al. Alirocumab and cardiovascular outcomes after acute coronary syndrome. N Engl J Med. 2018:379:2097-107

6. Nissen SE. Statin denial: an internet-driven cult with deadly consequences. Ann Intern Med. 2017;167:281-2.

7. Gupta A, Thompson D, Whitehouse A, Collier T, Dahlof B, Poulter N, et al. Adverse events associated with unblinded, but not with blinded, statin therapy in the Anglo-Scandinavian cardiac outcomes trial-lipid-lowering arm (ASCOT-LLA): a randomised double-blind placebo-controlled trial and its non-randomised non-blind extension phase. Lancet. 2017;389:2473-81.

8. Mach F, Ray KK, Wiklund O, Corsini A, Catapano AL, Bruckert E, et al. Adverse effects of statin therapy: perception vs. the evidence - focus on glucose homeostasis, cognitive, renal and hepatic function, haemorrhagic stroke and cataract. Eur Heart J. 2018;39:2526-39.

9. Mannarino MR, Sahebkar A, Bianconi V, Serban MC, Banach M, Pirro M. PCSK9 and neurocognitive function: should it be still an issue after FOURIER and EBBINGHAUS results? J Clin Lipidol. 2018:12:1123-32.

10. Murphy A, Faria-Neto JR, Al-Rasadi K, Blom D, Catapano A, Cuevas A, et al. World heart federation cholesterol roadmap. Glob Heart. 2017:12:179-97.

11. Yamashita S, Masuda D, Arai H, Matsuzawa Y. Cultural barriers in the treatment of dyslipidemia: a survey of Japanese physician attitudes. J Atheroscler Thromb. 2018;26:154-69.

12. Nordestgaard BG, Chapman MJ, Humphries SE, Ginsberg HN, Masana L, Descamps OS, et al. Familial hypercholesterolaemia is underdiagnosed and undertreated in the general population: guidance for clinicians to prevent coronary heart disease: consensus statement of the European atherosclerosis society. Eur Heart J. 2013;34:3478-90a.

13. Santos RD, Gidding SS, Hegele RA, Cuchel MA, Barter PJ, Watts GF, et al. Defining severe familial hypercholesterolaemia and the implications for clinical management: a consensus statement from the international atherosclerosis society severe familial hypercholesterolemia panel. Lancet Diabetes Endocrinol. 2016:4:850-61.

14. Mach F, Baigent C, Catapano AL, Koskinas KC, Casula M, Badimon L, et al. 2019 ESC/EAS guidelines for the management of dyslipidaemias: lipid modification to reduce cardiovascular risk. Eur Heart J. 2020;41: 111-88.

15. Kinoshita M, Yokote $K$, Arai H, lida M, Ishigaki Y, Ishibashi S, et al. Japan atherosclerosis society (JAS) guidelines for prevention of atherosclerotic cardiovascular diseases 2017. J Atheroscler Thromb. 2018;25:846-984.

16. Herdy AH, Lopez-Jimenez F, Terzic CP, Milani M, Stein R, Carvalho T, et al. South American guidelines for cardiovascular disease prevention and rehabilitation. Arq Bras Cardiol. 2014;103(2 Suppl 1):1-31.

17. Guerrero AE. 2015 clinical practice guidelines for the Management of Dyslipidemia in the Philippines - executive summary: dyslipidemia guidelines 2015. ASEAN Heart J. 2016;24:7.

18. Zhang X, Liu J, Wang M, Qi Y, Sun J, Liu J, et al. Twenty-year epidemiologic study on LDL-C levels in relation to the risks of atherosclerotic event, hemorrhagic stroke, and cancer death among young and middle-aged population in China. J Clin Lipidol. 2018;12:1179-89.

19. Ma C, Gurol ME, Huang Z, Lichtenstein AH, Wang X, Wang Y, et al. Lowdensity lipoprotein cholesterol and risk of intracerebral hemorrhage: a prospective study. Neurology. 2019;93:e445-e57.
20. Amarenco P, Kim JS, Labreuche J, Charles H, Abtan J, Béjot Y, et al. A comparison of two LDL cholesterol targets after ischemic stroke. N Engl J Med. 2019. https://doi.org/10.1056/NEJMoa1910355.

21. Giugliano RP, Mach F, Zavitz K, Kurtz C, Im K, Kanevsky E, et al. Cognitive function in a randomized trial of evolocumab. N Engl J Med. 2017;377:633-43

22. Bangalore S, Fayyad R, Hovingh GK, Laskey R, Vogt L, DeMicco DA, et al. Statin and the risk of renal-related serious adverse events: analysis from the IDEAL, TNT, CARDS, ASPEN, SPARCL, and other placebo-controlled trials. Am J Cardiol. 2014;113:2018-20.

23. Reiner Z, Sonicki Z, Tedeschi-Reiner E. Physicians' perception, knowledge and awareness of cardiovascular risk factors and adherence to prevention guidelines: the PERCRO-DOC survey. Atherosclerosis. 2010;213:598-603.

24. Presta V, Figliuzzi I, Miceli F, Coluccia R, Fogacci F, Cicero AFG, et al. Achievement of low density lipoprotein $(\mathrm{LDL})$ cholesterol targets in primary and secondary prevention: analysis of a large real practice database in Italy. Atherosclerosis. 2019;285:40-8.

25. März W, Dippel FW, Theobald K, Gorcyca K, lorga ŞR, Ansell D. Utilization of lipid-modifying therapy and low-density lipoprotein cholesterol goal attainment in patients at high and very-high cardiovascular risk: real-world evidence from Germany. Atherosclerosis. 2018;268:99-107.

26. Danchin N, Almahmeed W, Al-Rasadi K, Azuri J, Berrah A, Cuneo CA, et al. Achievement of low-density lipoprotein cholesterol goals in 18 countries outside Western Europe: the international ChoLesterol management practice study (ICLPS). Eur J Prev Cardiol. 2018;25:1087-94.

\section{Publisher's Note}

Springer Nature remains neutral with regard to jurisdictional claims in published maps and institutional affiliations.
Ready to submit your research? Choose BMC and benefit from:
- fast, convenient online submission
- thorough peer review by experienced researchers in your field
- rapid publication on acceptance
- support for research data, including large and complex data types
- gold Open Access which fosters wider collaboration and increased citations
- maximum visibility for your research: over $100 \mathrm{M}$ website views per year
At BMC, research is always in progress.
Learn more biomedcentral.com/submissions 